\title{
Makerspace-based Innovation and Entrepreneurship Education System in Higher Education
}

\author{
Lanyong Zhang \\ College of Automation \\ Harbin Engineering University \\ Harbin, China
}

\author{
Jiajia Zhou, Qiang Pan, Liang Li, Hongdan Liu \\ College of Automation \\ Harbin Engineering University \\ Harbin, China
}

\begin{abstract}
This paper focuses on facilitating innovation and entrepreneurship by removing barriers between higher education institutions and incubation centers, between incubation centers and enterprises, and in higher education institutions to provide college students with technological, incubating, financing, and market-access guidance. A school-enterprise coalition mechanism for undergraduate innovation and entrepreneurship is established to construct a makerspace-based undergraduate innovation and entrepreneurship system using project demand as the direction, technological innovation as the essence, and effective incubation as the method. This helps remove the barriers to innovation and entrepreneurship and solve key issues like underdeveloped incubation mechanisms for innovation and entrepreneurship and uncertain market demand, which provides a feasible way for innovation and entrepreneurship to college students.
\end{abstract}

Keywords-Innovation and entrepreneurship; makerspace; coalition of schools and enterprises; technological innovation

\section{RESEARCH BACKGROUND AND ITS SigNIFICANCE}

As college students are valuable human resources, their innovation and entrepreneurship give significant impetus to mass entrepreneurship and innovation. The Central Committee of the Communist Party of China (CPC) and the State Council issued documents including the Opinions of the CPC Central Committee and the State Council on Deepening the Reform of Mechanism and System to Accelerate the Implementation of Innovation-Driven Development Strategy (Central Party Document No. 8, 2015), the Opinions of the State Council on Further Efforts to Promote Employment and Entrepreneurship under the New Conditions (State Council Document No. 23, 2015), and the Opinions of the General Office of the State Council on Deepening the Reform of Innovation and Entrepreneurship Education in Higher Education Institutions (State Council Document No. 36, 2015). This increases the support currently provided for the innovation and entrepreneurship by college students, which include undergraduates in all types of institutions, graduates of all types of institutions within five years of graduation, and overseas returnees. The provincial government of Heilongjiang issued Several Opinions by Heilongjiang People’s Government

Project Support: Heilongjiang Education Science “13th Five-Year” Plan 2017 Projects (GBD1317115), Harbin Engineering University Undergraduate Education Reform Project (JG2017B16), Chinese Society of Academic Degrees and Graduate Education Project (B-2017Y0504-075), and Harbin Engineering University Higher Education Research Institute Key Projects (2018-2). on Promoting Innovation and Entrepreneurship among College Students (Heilongjiang Government Document No. 16, 2015), which proposes improving the teaching system for training students on innovation and entrepreneurship and encourages teachers to guide the students in innovation and entrepreneurship. For college students, it suggests establishing entrepreneurship internship bases, education bases for off-campus practice, entrepreneurship demonstration bases, internship bases for technological entrepreneurship, and training bases for vocational colleges. Focusing on higher education institutions, it proposes the integration of social and corporate resources for entrepreneurial training and employment of professionals as well as part-time instructors from enterprises.

As college students are able to perceive social, economic, and industrial development trends after acquiring professional knowledge at schools, they are a major group with potential for innovation and entrepreneurship. They are at a critical stage in the process of the formation of personal values, which is significantly influenced by innovation and entrepreneurship education. Hence, higher education that focuses on innovation and entrepreneurship plays an important role. Its implementation is highly valued by the Chinese government.

Makerspace provides training platforms for such education. Innovation and entrepreneurship education requires more practice than other types of education. The traditional approach tends to equip students with theoretical knowledge and mostly includes simulated practice. Meanwhile, innovation and entrepreneurship education based on makerspace largely consists of real-life practice. This is a type of practical and experiential education. Makerspace can become a powerful supplement for innovation and entrepreneurship education in higher education institutions.

\section{Status Quo of Domestic AND Overseas Research}

The number of college graduates in China reached 7.27 million in 2014 and a record high of 7.49 million in 2015. However, only around $1 \%$ of these college students are currently engaged in entrepreneurship, compared with, according to the statistics by a US-based education research agency, $20-30 \%$ in the U.S., which is much higher than the average ratio of around $2 \%$ in developing countries. This shows that there is a gap between China and other countries in 
terms of entrepreneurship among college students; yet, this gap is exactly where the potential for national development lies. At the same time, higher education teachers also shoulder the critical responsibility to narrow this gap.

The definition of makerspace can be traced back to September 2014, when Premier Li Keqiang proposed for the first time at the opening ceremony of the Summer Davos Forum "a new wave of mass and grass-root entrepreneurship and a new trend of mass innovation.” On January 4, 2015, during his inspection of Chaihuo Makerspace in Shenzhen, Li praised that "the young makers sufficiently meet the market demand and have infinite creativity" and that they "fully demonstrate the dynamics of mass entrepreneurship and innovation, and such dynamics and creativity will become the unfailing engine for China's future economic growth.” On January 28, 2015, at the Executive Meeting of the State Council, summoned and presided by Premier $\mathrm{Li}$, policies and measures favorable to the development of makerspace were proposed, including "the establishment of entrepreneurial service platforms, such as makerspace, for everyone" and "the cultivation of a variety of talents among college students and focusing on teambuilding."

Makerspace is a new, low-cost, convenient, total-factor, and open service platform for innovation and entrepreneurship established through market mechanism, professional services, and capitalization that fully utilizes the Internet and open source technology. It provides cyberspace as well as physical spaces for entrepreneurs to work, socialize, and share resources. To put it simply, it provides innovators and entrepreneurs with spaces that are "good" and "comprehensive"- "good" because of their low cost, absence of threshold, and provision of specialized services for the masses; "comprehensive" because of the innovation-entrepreneurship, offline-online, and incubation-investment integration that satisfies all the needs with respect to innovation and entrepreneurship.

III. SCHOOL-ENTERPRISE COALITION FOR ESTABLISHING AN INNOVATION AND ENTREPRENEURSHIP SYSTEM FOR COLLEGE

\section{STUDENTS}

\section{A. Construction of a Makerspace-based Innovation and Entrepreneurship System for College Students}

In accordance with the principles of knowledge transfer, ability development, and qualitative improvement, the content of innovation and entrepreneurship education is optimized and reorganized based on makerspace to establish an innovative entrepreneurship education system that revolves around the cultivation of high-quality innovative talents.

According to statistics, in terms of the coverage and total amount of knowledge, innovation and entrepreneurship education based on makerspace far outweighs higher education institutions, government departments, or any education institution that specializes in related industries. The comprehensiveness of makerspace education is reflected in its coverage of the complete process of innovation and entrepreneurship based on a specific industry, from inspiring the creativity of innovators and entrepreneurs, to research and development, business model development, road show, financing, registration, and incubation. Innovators and entrepreneurs can acquire almost all kinds of necessary knowledge in medium- and large-scale makerspaces. At the same time, different contents of makerspace-based innovation and entrepreneurship education should be deeply integrated into industries. As this education model is driven by demand, its contents should be clearly divided into small sections. At the inception of courses and training on innovation and entrepreneurship, it is necessary to identify the abilities that will be acquired through these courses and training, establish the ability structure model, and design related courses and training based on this model. After amendments and improvements, a sophisticated course system is eventually developed. The ability-driven education system manifests the learners' overall educational needs.

\section{B. Remove Barriers to Innovation and Entrepreneurship} Using Project Demand as the Direction, Technological Innovation as the Essence, and Effective Incubation as the Method

Under the guidance of scientific research programs in related institutions, a group of lower-grade students who are interested in scientific research are selected through this project, so as to establish innovation laboratories for college students. This ensures that throughout their four years of college study, the students can develop in the technological environment of the school, enterprises, and laboratories. They are provided with the conditions for innovation, invention, design, and production and encouraged to participate in various design competitions. Under the leadership and guidance of the Science Park Incubation Center of Harbin Engineering University, technological creations that have significant market potential are selected for incubation, so as to transform them into technological commodities that are qualified for market access.

An innovation and entrepreneurship system for college students based on makerspace is established. This system adheres to the principle of "cross-disciplinary and collaborative innovation" and adapts to new trends in technological innovation. Advanced development of technological innovation requires high-end research methods as well as cross-disciplinary and multidimensional collaboration of upstream and downstream technologies. Educational institutions should encourage teachers and students to engage in innovative and entrepreneurial activities based on a cross-disciplinary, cross-professional, and multi-institutional cooperative model. In recent years, Harbin Engineering University has leveraged disciplines with distinctive advantages_-including naval architecture and marine engineering, underwater acoustic technology, power engineering and engineering thermo-physics, and control science and engineering - to integrate various social resources and nurture new growth areas in technological innovation and industrial chains with the characteristics of the shipping and marine field. It also encourages the cooperation of its teachers and students with distinguished domestic and foreign scholars to acquire new knowledge, methods, and technological progress. It cooperates with prestigious Chinese enterprises to explore enterprises' major needs for marketization and engineering thinking. A diverse, innovative, and entrepreneurial course system of collaboration between the first and the second classrooms is gradually established. A three-tier 
model for cultivating innovative and entrepreneurial talents that entails learning, experiences, and business startup is also constructed to combine innovation and entrepreneurship education with professional education and develop students' inter-disciplinary and cross-disciplinary innovation ability.

\section{Research on Diversification of Innovation and Entrepreneurship Education Methods}

A wide variety of education methods are used to provide innovation and entrepreneurship education to entrepreneurs who can choose according to their interests and development needs. There should be great diversity in methods used for makerspace-based innovation and entrepreneurship education, covering both formal and informal learning. Besides self-learning, the main education methods include courses, lectures, coaching, workshops, seminars, competitions, experiential activities, and practical activities. Such diversity allows makerspace-based innovation and entrepreneurship education to use different education methods flexibly according to the topics being covered and level of interaction.

Due to such diversity, the selection of teaching methods for makerspace-based innovation and entrepreneurship education also becomes more flexible and diverse. Apart from traditional lecturing, methods like case teaching, experiential teaching, and simulation education are also available.

Harbin Engineering University encourages research on the diversification of education methods by offering a course on innovation and entrepreneurship, Introduction to the Technological Innovation of Internet of Things, for the whole school. Entrepreneurs from enterprises are invited to teach entrepreneurship. Talks, seminars, and practices are adopted to extend the coverage and boost the level of interaction of innovation and entrepreneurship education. The university also utilizes talent innovation programs of the Harbin Municipal Science and Technology Bureau, the China Engineering Robot Contest, and "the Internet Plus" Contest to improve incubation methods and efficiency, thereby allowing more products to enter the market.

\section{School-enterprise Coalition for Establishing Innovation and Entrepreneurship Education System}

An innovation and entrepreneurship system for college students based on maker space is established through the coalition of the Science Park Entrepreneurship Incubation Center of the Harbin Engineering University and the CSIC 703 Research Institute. By utilizing the model of "innovation integrated with professional education and leading entrepreneurship and entrepreneurship integrated with professional education and employment generation," Harbin Engineering University combines innovation and entrepreneurship education with different disciplines, cross-disciplinary education, and industrial development and encourages students to set up or buy into companies, industrializing their technological creations and launching them into the market.

Since innovation and entrepreneurship education based on makerspace is demand-driven, its contents should be more distinctively fragmented. At the inception of courses and training on innovation and entrepreneurship, it is necessary to identify the abilities that will be acquired through these courses and training, establish the ability structure model, and design related courses and training based on this model. After amendments and improvements, a sophisticated course system is eventually developed. The ability-driven education system manifests the learners' overall educational needs. The wide and comprehensive contents of makerspace-based innovation and entrepreneurship education must be divided into the smallest "fragments" from which innovators and entrepreneurs with different demands can select freely and assemble their own "education platters."

\section{PROMOTION AND APPLICATION OF INNOVATION AND \\ ENTREPRENEURSHIP EDUCATION SYSTEM FOR COLLEGE STUDENTS}

Through the research and activities in this paper, innovative young talents and teams including college students are cultivated at higher education institutions, so as to form an innovation and entrepreneurship culture with diverse formats and distinctive characteristics. Through the Science Park Entrepreneurship Incubation Center of Harbin Engineering University, makerspace is transformed into a place for the communication and implementation of technological innovation activities, technology accumulation, and generation, realization, and exchange of creativity, thereby becoming an innovation and entrepreneurship hub.

Author Summary: Zhang Lanyong (1983-), vice professor, master's supervisor and Party Branch Secretary of Automation Engineering Research Institute of Automation College, Harbin Engineering University. His research orientation is innovation and entrepreneurship education for college students.

\section{REFERENCES}

[1] Hao Jie, Wu Aihua, Hou Yongfeng. Establishment and Elevation of the U.S. Innovation and Entrepreneurship Education System[J]. Research in Higher Education of Engineering, 2016, 2:7-12

[2] Zhang Lanyong, Liu Sheng, Li Bing, Sun Rong, Tian Kai. The research in and practice of innovation education and enterprise education in colleges. Advances in Education Research, 2013, Vol. 23:185-189

[3] Ma Yongbin, Bai Zhe. Research and Exploration regarding the Practice Model of Innovation and Entrepreneurship Education in Universities[J]. Tsinghua Journal of Education, 2015, 36(6):99-103

[4] Zhang Lanyong, Liu Sheng, Tian Kai, Chen Mingjie, Pan Qiang. Exploration of the Industry-University Research Collaborative Mechanism for Cultivating Innovation Talents Using Information Technologies[J]. China Information Technology Education, 2014, 4:73-74

[5] Zhang Weiguo, Xuan Xingyu. Interactive Development of High-efficiency Entrepreneurship Education and Makerspace Based on Social Exchange Theory[J]. China Higher Education Research, 2016, 10:93-97

[6] Zhang Lanyong, Liu Sheng, Li Bing, Sun Rong. Cultivation of University Students' Innovation and Entrepreneurship Abilities through the Application of Information Technologies[J]. China Information Technology Education, 2014, 8:62-63

[7] Li Shuangshou, Yang Jianxin. Establishment and Practice of a High-efficiency Makerspace: Using the Example of Tsinghua University i.Center [J]. Modern Educational Technology, 2015,25(5):5-11

[8] Zhang Lanyong, Liu Sheng. The training methods of scientific and technological innovation ability of college students specialty based on innovation and entrepreneurship[C]. International conference on social science and higher education, Sanya, Dec 26-27, 2015:404-407 
[9] Wang Zhanren, Liu Haibin, Li Zhongyuan. Research on the Role of Makerspace in Innovation and Entrepreneurship Education in Higher Education: Based on the Field Visits and Investigation of 25 Makerspaces Across 6 Chinese Cities[J]. Ideological \& Theoretical Education, 2016, 2:85-91
[10] Reviews and Thoughts on Innovation and Entrepreneurship Education in Higher Education during the "12th Five-Year" Period: Based on an Analysis of the Third-Party Evaluation Report on Higher Education[J]. China Higher Education Research, 2016,2:20-28 